\title{
AKTIVASI ARANG SEKAM PADI DENGAN LARUTAN NATRIUM KARBONAT DAN KARAKTERISASINYA
}

\author{
Solihudin*, Atiek Rostika Noviyanti, \& Rukiah \\ Departemen Kimia, Fakultas Matematika dan Ilmu Pengetahuan Alam, Universitas Padjadjaran \\ *Alamat korespodensi :solihudin@unpad.ac.id
}

\begin{abstract}
Abstrak: Sekam padi merupakan limbah pertanian yang cukup melimpah di daerah penghasil beras sepeti Jawa Barat, sangat potensial untuk dimanfaatkan sebagai sumber karbon karbon aktif yang dapat digunakan untuk adsorben, pendukung katalis dan elektrode. Sampai saat ini telah banyak penelitian pembuatan karbon aktif dari sekam padi namun masih menggunakan metode dan bahan kimia yang kurang ramah lingkungan serta biaya tinggi. Pada penelitian ini aktivasi arang sekam padi dilakukan dengan metode refluks menggunakan larutan natrium karbonat untuk melarutkan silikanya. Tujuan penelitian ini adalah untuk mengetahui pengaruh rasio mol silika dalam arang sekam padi dengan natrium karbonat, waktu refluks, dan suhu kalsinasi terhadap karakteristik karbon aktif yang dihasilkan. Metode yang digunakan adalah pelarutan silika oleh natrium karbonat dengan cara refluks kemudian dikalsinasi. Hasil aktivasi karbon tersebut dikarakterisasi dengan uji kadar abu, XRD, SEMEDS, dan FTIR. Dari hasil penelitian ini didapatkan kondisi optimum aktivasi arang sekam padi yaitu rasio mol natrium karbonat dengan silika yaitu 1:3, waktu refluks selama 3 jam, dan suhu kalsinasi $900^{\circ} \mathrm{C}$ serta karbon yang didapatkan berupa amorf.
\end{abstract}

Kata kunci: aktivasi arang, arang sekam padi, karbon aktif, natrium karbonat

\begin{abstract}
Rice husk is one of agriculture wastes that is abundant in rice producer area such as West Java and has potency as an active carbon source that can be used as adsorbent, catalyst support and electrode. Up until today, many studies develop active carbon fabrication from rice husk but still using methods and chemicals that are not environmentally friendly and expensive. In the present study, activation of rice husk charcoal was conducted using reflux method by sodium carbonate solution to dissolve the silica content. The objective of the present study was to determine the effect of mole ratio of silica in rice husk to sodium carbonat, reflux time and calcination temperature on the characteristics of the active carbon. The methods conducted were dissolution of silica with sodium carbonate solution using reflux method followed by calcination. The resulting activated carbon was characterized for its ash content, XRD, SEM-EDS, and FTIR. The results of the present study indicate that the optimum condition for activated rice husk charcoal is 1:3 for mole ratio of sodium carbonate to silica, 3 hours for reflux time, and calcination temperarture at $900^{\circ} \mathrm{C}$. The carbon product was amorf solid.
\end{abstract}

Keywords: charcoal activation, rice husk charchoal, activated carbon, sodium carbonate

\section{PENDAHULUAN}

Salah satu sumber karbon yang melimpah, terbarukan dan murah adalah sekam padi yang merupakan produk samping pada penggilingan padi. Komponen utama dari sekam padi adalah selulosa $(38 \%)$, hemiselulosa (18\%), lignin $(22 \%)$, dan $\mathrm{SiO}_{2}$ (19\%) (Worasuwannarak et al., 2007). Banyaknya kandungan senyawa karbon dan silika dalam sekam padi sehingga produk kabonisasinya berupa komposit karbon-silika.

Bahan karbon berpori telah banyak menarik minat peneliti dalam beberapa tahun terakhir, karena berpotensi untuk digunakan dalam berbagai bidang terutama di sebagai pendukung katalis, elektrode baterai, kapasitor, penyimpan gas dan rekayasa lainnya (Farag et al., 1998; Frackowiak \& Beguin, 2001). Karbon aktif dari sekam padi dapat diperoleh melalui proses karbonisasi yang dilanjutkan dengan proses aktivasi. Proses aktivasi arang sekam padi untuk mendapatkan karbon aktif yang luas permukaan tinggi umumnya melalui penghilangan kandungan silika. Guo et al. (2002) membuat karbon aktif dari sekam padi dengan cara aktivasi arang sekam padi dengan aktivator kalium hidroksida dan natrium hidroksida pada suhu aktivasi $700^{\circ} \mathrm{C}$ dan $800^{\circ} \mathrm{C}$. Aktivasi dengan kalium hidroksida menghasilkan karbon aktif dengan luas permukaan sekitar 3000 $\mathrm{m}^{2} \cdot \mathrm{g}^{-1}$. Yeletsky et al. (2009) menggunakan aktivator kalium karbonat dengan suhu aktivasi $900^{\circ} \mathrm{C}$ menghasilkan karbon aktif dengan luas permukaan maksimum mencapai $1676 \mathrm{~m}^{2} \cdot \mathrm{g}^{-1}$. Aktivasi arang sekam juga dapat dilakukan melalui impregnasi dengan seng klorida yang menghasilkan karbon aktif dengan luas permukaan $1555 \mathrm{~m}^{2} \cdot \mathrm{g}^{-1}$ (Lu et al., 2009). Pada proses aktivasi tersebut menggunakan basa yang bersifat korosif dan pada suhu tinggi sehingga memerlukan peralatan kualitas khusus sehingga memerlukan biaya tinggi. Karbon aktif dari sekam padi juga dapat diperoleh dengan cara menghilangkan silika yang terkandung dalam sekam padi dengan menggunakan hidrogenfluorida sebelum karbonisasi, kemudian diaktivasi dengan uap air (Deiana et al., 
2008). Pada proses aktivasi ini diperlukan penanganan khusus karena dihasilkan gas silikon tetrafluorida yang apabila dibuang ke udara secara langsung berpotensi mencemari lingkungan.

Seperti yang diuraikan dalam beberapa pustaka menunjukkan masih adanya kelemahan dalam pembuatan karbon aktif seperti prosesnya yang masih rumit, memerlukan energi tinggi dan tidak ramah lingkungan. Pada penelitian ini dilakukan karbonisasi pada suhu rendah kemudian dilanjutkan dengan proses pelarutan silika dengan larutan natrium karbonat secara refluks. Pada proses yang akan diteliti ini diperoleh karbon aktif dan larutan natrium karbonat yang mengandung endapan silika. Larutan natrium karbonatnya dapat digunakan kembali untuk proses pelarutan silika (Liu et al., 2011; Liu et al., 2012).

\section{BAHAN DAN METODE}

Pada penelitian ini dilakukan pelepasan silika pada arang sekam padi dengan larutan natrium karbonat. Tahap persiapan sampel sekam padi meliputi pengadaan, karakterisasi awal dan pembersihan sekam padi dari pengotor. Tahap berikutnya karbonisasi pada suhu rendah $\left(400^{\circ} \mathrm{C}\right)$ untuk mendapatkan arang, aktivasi dengan larutan natrium karbonat pada konsentrasi dan suhunya yang diragamkan. Produknya dikarakterisasi meliputi: komposisi (EDX), struktur (FTIR dan XRD), morfologi permukaan (SEM) dan konduktivitas.

\section{Alat dan Bahan \\ Alat-alat}

Alat yang digunakan pada penelitian ini adalah alat-alat gelas, corong buchner, desikator, penyaring 100 mesh, indikator $\mathrm{pH}$ universal, pemanas listrik, pengaduk magnetik, mortar, oven, tanur, neraca analitis, X-ray difractometer (XRD), Fourier Transform Infrared Spectroscopy (FTIR) dan Scanning Electron Microscope (SEM).

\section{Bahan-Bahan}

Bahan utama yang digunakan dalam penelitian ini adalah sekam padi dari penggilingan padi di Jatinangor Sumedang. Natrium karbonat sebagai pengektraksi kualitas ACS dari produk Emerck. Asam klorida dan asam nitrat untuk menghilangkan pengotor dan mengatur suasana.

\section{Metode Penelitian \\ Preparasi Arang dari Sekam Padi}

Sekam padi kering yang berasal dari tempat penggilingan padi di Jatinangor, Sumedang-Jawa Barat sebanyak $400 \mathrm{~g}$ dikarbonisasi pada tanur listrik dengan suhu karbonisasi $400^{\circ} \mathrm{C}$ selama 4 jam. Selanjutnya arang sekam padi yang diperoleh digerus sampai lolos pada saringan 100 mesh dan diukur kadar abunya.

\section{Aktivasi arang sekam padi}

Arang sekam padi ditimbang sebanyak $50 \mathrm{~g}$, kemudian ditimbang alkali karbonat ( $\mathrm{Na}$ atau $\mathrm{K}$ ) sehinnga diperoleh rasio silika-alkali karbonat 1:1, $1: 1,5,1: 2$, dan 1:3. Kemudian masing-masing ditambahkan $300 \mathrm{~mL}$ akuades kemudian direfluks selama 1 jam, disaring panas-panas dengan kertas saring Whatman No. 40 menggunakan corong Buchner dan dicuci dengan air panas sampai $\mathrm{pH}$ netral. Residu (karbon) dipisahkan, dikeringkan dalam oven pada suhu $110^{\circ} \mathrm{C}$ selama 4 jam, lalu ditimbang. Selanjutnya direfluks dengan asam nitrat $1 \mathrm{M}$ selama 2 jam. Kemudian didinginkan, disaring dengan corong buchner. Kemudian endapan dicuci dengan air suling sampai $\mathrm{pH}$ mendekati netral dan dikeringkan dalam oven pada suhu $110^{\circ} \mathrm{C}$, didinginkan dan ditimbang. Serbuk arang sekam padi yang relatif bebas pengotor logam, kemudian dikarakterisasi dengan menggunakan SEM-EDX.

\section{Kalsinasi}

Arang hasil aktivasi dengan kadar abu paling rendah, kemudian dimasukkan lagi dalam tanur untuk proses karbonisasi tahap kedua pada suhu 500, 700, dan $900^{\circ} \mathrm{C}$ selama 2 jam. Pada proses karbonisasi tahap kedua ini, ke dalam tanur yang berisi serbuk arang dialirkan gas argon dengan laju $0,5 \mathrm{~mL} /$ detik.

\section{Karakterisasi}

Struktur karbon hasil aktivasi arang ditentukan berdasarkan analisis X-ray Diffraction (XRD). Gugus fungsi sampel ditentukan dengan menggunakan Fourier Transform Infrared Spectroscopy (FTIR). Morfologi partikel karbon diukur dengan menggunakan Scanning Electron Microscope (SEM), dan juga diukur daya hantar listriknya.

\section{HASIL DAN PEMBAHASAN}

Sekam padi yang diperoleh dari penggilingan padi di Jatinangor dimasukkan dalam untuk memisahkan kotoran seperti pasir, tanah dan debu. Setelah dikeringkan, sekam padi dikarbonisasi dengan menggunakan alat karbonisasi pada suhu $400^{\circ} \mathrm{C}$ selama 4 jam untuk mendapatkan arang (Gambar 1). Pada proses ini senyawa organik yang ada dalam sekam padi mengalami pirolisis sehingga terbentuk arang yang disertai dengan perubahan berat akibat penguraian senyawa organik tersebut. Karbonisasi tidak dilakukan di lingkungan udara bebas (atmosfer udara) karena mulai dari suhu $350^{\circ} \mathrm{C}$ karbon yang terdapat dalam arang akan terbakar. Pada proses ini senyawa-senyawa hasil pirolisis yang mudah menguap akan terlepas dan unsur karbon serta senyawa anorganik lainnya akan tertinggal sebagai arang (Bharadwaj et al., 2004). Perolehan arang pada karbonisasi suhu $400^{\circ} \mathrm{C}$ sekira $40 \%$ dengan kadar abunya sekira 54\%. Kadar abu ini dijadikan dasar untuk menentukan jumlah pengekstraksi yang digunakan dengan asumsi semua abu merupakan silika. 


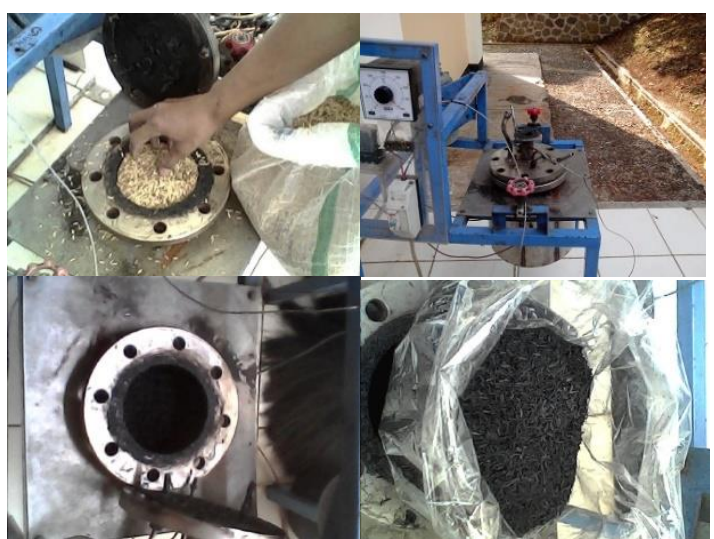

Gambar 1. Gambar karbonisasi sekam padi pada suhu $400^{\circ} \mathrm{C}$

\section{Karakterisasi arang sekam padi}

Untuk mengetahui unsur-unsur dan morfologi arang sekam padi, maka dilakukan karakterisasi menggunakan SEM-EDX. Hasil pemetaan unsur utama pada arang sekam padi menunjukkan silikon dan oksigen paling banyak terdapat di permukaan bagian luar (Gambar 2). Hal tersebut menunjukkan silikon pada sekam padi terdapat sebagai silika $\left(\mathrm{SiO}_{2}\right)$. Hasil analisis komposisi pada berbagai bagian pada arang (Gambar 3) menunjukkan pada bagian permukaan luar mengandung silika mencapai 5,31 kali dari karbon (Gambar 3C). Unsur-unsur lain yang terdeteksi oleh EDX adalah aluminium, kalium dan fosfor.
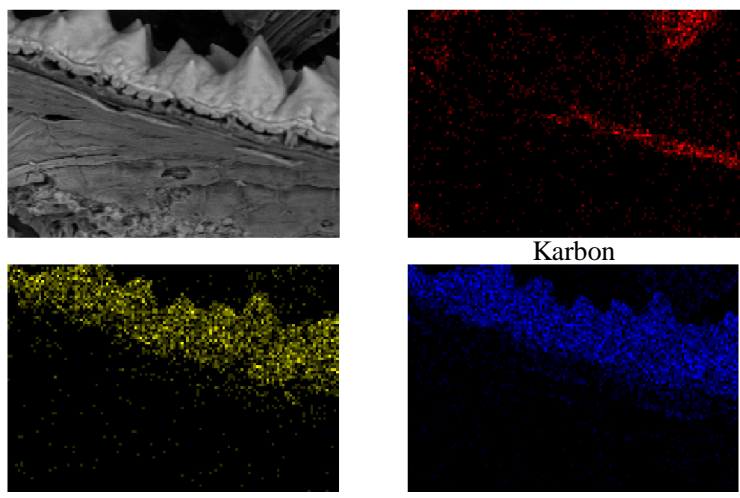

Oksigen

Silikon

Gambar 1. Pemetaan unsur utama dengan EDX pada arang sekam padi
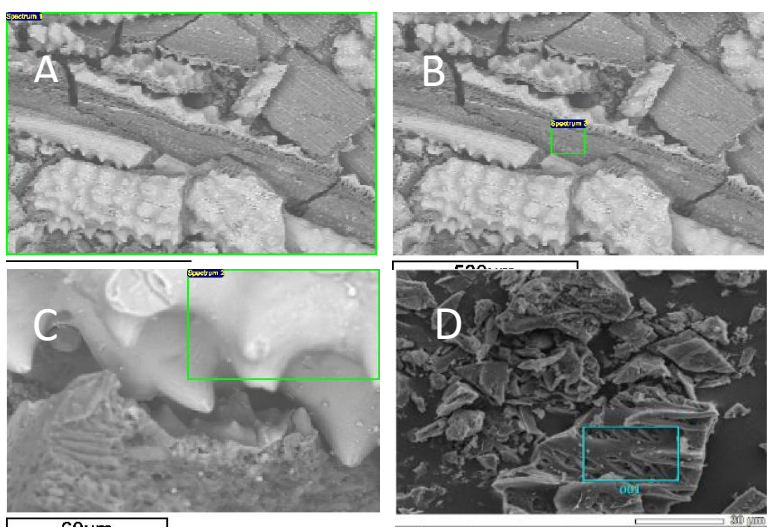

\begin{tabular}{ccccc}
\hline Komponen & $\mathrm{A}$ & $\mathrm{B}$ & $\mathrm{C}$ & $\mathrm{D}$ \\
\hline $\mathrm{C} / \%$ & 58.18 & 70.55 & 23.77 & 64.84 \\
$\mathrm{SiO}_{2} / \%$ & 38.96 & 26.58 & 75.19 & 35.164 \\
$\mathrm{Al}_{2} \mathrm{O}_{3} / \%$ & 1.45 & - & - & - \\
$\mathrm{K}_{2} \mathrm{O} / \%$ & 1.41 & 1.65 & 1.03 & - \\
$\mathrm{P}_{2} \mathrm{O}_{5} / \%$ & - & 1.23 & - & - \\
\hline
\end{tabular}

Gambar 2. Analisis EDS pada beberapa bagian arang

Karakterisasi dengan FTIR dilakukan untuk mengetahui gugus fungsi yang terdapat dalam arang sekam padi hasil preparasi, spektrum FTIR dicantumkan pada Gambar 4. Pada spektrum FTIR tersebut terdapat pita serapan pada bilangan gelombang $3424 \mathrm{~cm}^{-1}, 2927 \mathrm{~cm}^{-1}, 1698 \mathrm{~cm}^{-1}, 1607$ $\mathrm{cm}^{-1}, 1088 \mathrm{~cm}^{-1}, 822 \mathrm{~cm}^{-1}$, dan $469 \mathrm{~cm}^{-1}$ yang masingmasing mengidentifikasikan adanya regang vibrasi $\mathrm{O}$ $\mathrm{H}$, regang vibrasi alifatik $\mathrm{C}-\mathrm{H}$, regang vibrasi $\mathrm{C}=\mathrm{O}$, gugus $\mathrm{C}=\mathrm{C}$, regang asimetri $\mathrm{Si}-\mathrm{O}-\mathrm{Si}$, vibrasi tetrahedral $\mathrm{SiO} 4$ dan vibrasi bending $\mathrm{Si}-\mathrm{O}-\mathrm{Si}$.

\section{Pelepasan silika}

Variasi rasio mol pengekstraksi terhadap kandungan silika pada arang dilakukan untuk mengetahui rasio terbaik untuk pelepasan silika sehingga diperoleh karbon yang murni. Hasilnya dapat dilihat pada Gambar 5 yang menjelaskan kadar abu yang diperoleh pada masing-masing rasio pengekstraksi dengan waktu refluks 1 jam. Pada Gambar 5 tersebut dengan jelas terlihat turunnya kandungan silika pada arang sekam padi dengan bertambahnya rasio pengekstraksi, hal ini menunjukkan telah terlepasnya silika dari arang sekam padi. Karbon yang memiliki kadar abu yang paling rendah diperoleh dari proses pelepasan dengan rasio mol pengekstraksi dengan silika 3 . 


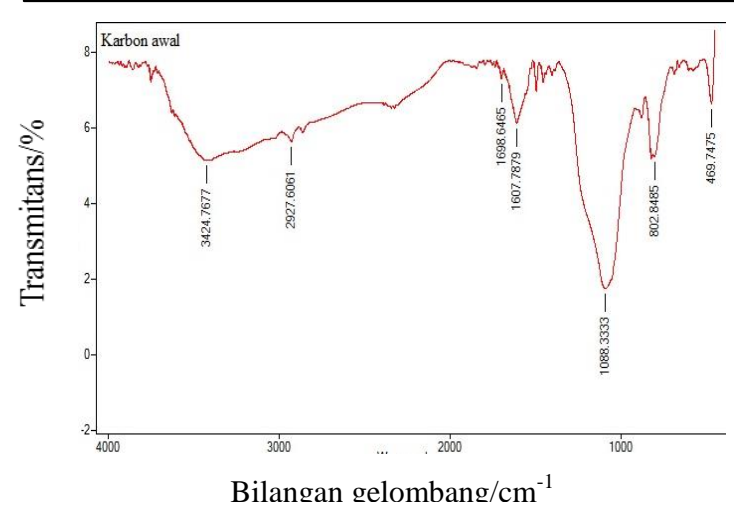

Gambar 4. Spektrum hasil pengukuran FTIR arang sekam padi hasil preparasi

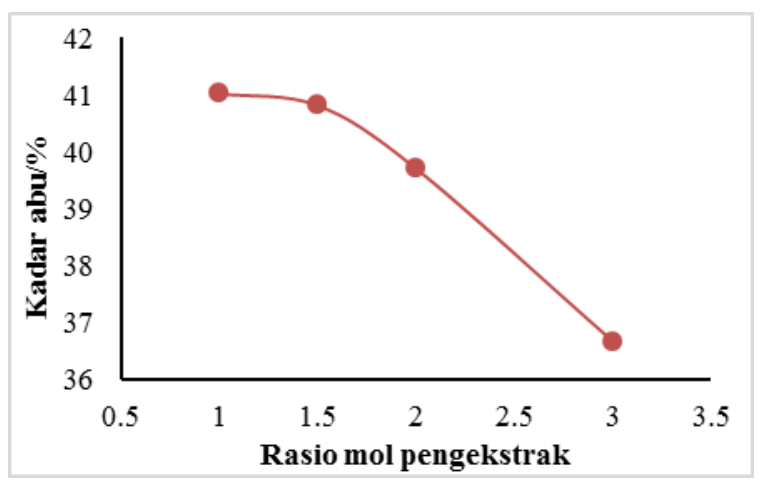

Gambar 3. Pengaruh rasio mol pengekstraksi/silika terhadap kadar abu

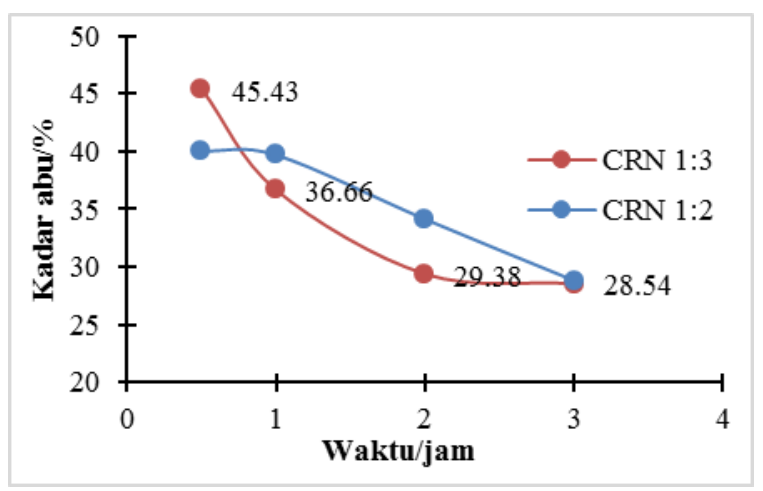

Gambar 4. Pengaruh waktu refluks terhadap kadar abu

Variasi waktu refluks dilakukan pada rasio pengekstraksi/silika 3 dan 2 dicantumkan pada Gambar 6. Pelepasan silika melalui proses refluks dengan larutan natrium karbonat rasio pengekstraksi/silika 3 selama 2 jam dan 3 jam menunjukkan kadar abu dalam arang tidak jauh berbeda yaitu masing-masing $29,38 \%$ dan $28,54 \%$. Dengan demikian pelepasan silika dalam arang sekam padi dengan larutan natrium karbonat dapat dilakukan lebih dari 2 jam, namun pada penelitian ini waktu refluks selanjutnya dilakukan selama 3 jam. Kandungan silika sangat berpengaruh pada kualitas arang yang dihasilkan. Keberadaan silika dapat menyebabkan terjadinya penyumbatan pori-pori pada arang sehingga luas permukaan arang menjadi berkurang. Selain itu silika bersifat isolatif sehingga dapat mempengaruhi konduktivitas karbon yang diperoleh.

\section{Kalsinasi}

Arang yang telah dihilangkan silikanya kemudian dikalsinasi pada suhu yang divariasikan $\left(500,700\right.$, dan $\left.900^{\circ} \mathrm{C}\right)$ selama 2 jam dalam kondisi atmosfer gas argon. Fungsi kalsinasi adalah untuk meningkatkan derajat karbonisasi. Karena suhu tinggi mampu menghilangkan komponen-komponen mudah menguap pada arang sehingga dapat meningkatkan kadar karbon dan menambah keteraturan strukturnya. Keteraturan struktur akan berkaitan dengan nilai konduktivitas (sifat pengantaran listrik).

Gambar 7 merupakan grafik persentase karbon yang diperoleh setelah proses kalsinasi variasi suhu yang dialiri gas argon. Persentase karbon berkurang dengan meningkatnya suhu kalsinasi, hal ini dikarenakan semakin banyaknya zat-zat yang mudah menguap yang hilang dari karbon sekam padi sehingga kemurnian karbon akan semakin meningkat.

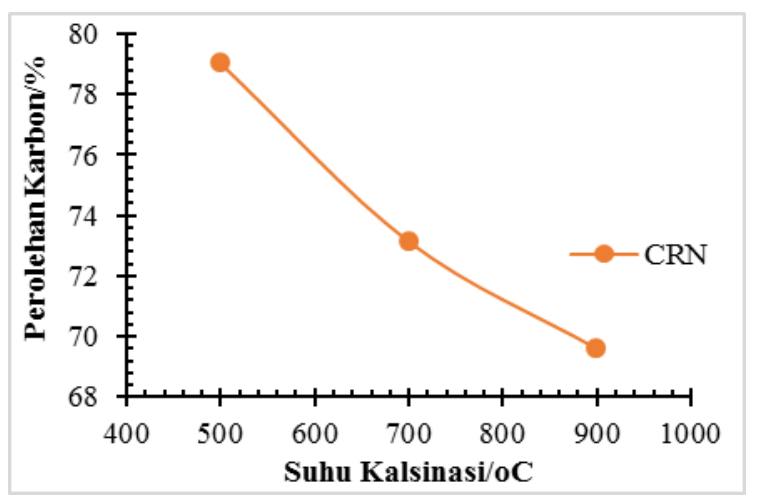

Gambar 5. Grafik persentase karbon yang diperoleh pada proses kalsinasi

\section{Uji Konduktivitas}

Penentuan nilai konduktivitas menggunakan metode four line probe, pelet karbon dijepit pada 4 garis sejajar yang kemudian dialiri arus konstan dari $0,1 \mathrm{~mA}-0,5 \mathrm{~mA}$, tegangan akan terukur dari alat voltmeter yang dihubungkan ke alat tersebut. Dari kedua nilai ini dapat dihitung nilai konduktivitasnya. Peningkatan nilai konduktivitas dengan bertambahnya suhu kalsinasi seperti ditunjukkan pada Gambar 8. Nilai konduktivitas karbon sekam padi tertinggi yaitu 6,04 S.m ${ }^{-1}$ pada suhu kalsinasi $900^{\circ} \mathrm{C}$. Nilai konduktivitas tersebut terletak pada daerah nilai konduktivitas listrik yang dimiliki oleh material semikonduktor yaitu terletak pada nilai $10^{-8}$ S.m ${ }^{-1}$ sampai $10^{3} \mathrm{~S} . \mathrm{m}^{-1}$. Hasil ini jika dibandingkan dengan carbon black dari sekam padi hasil penelitian Wang et al. (2011) memiliki nilai konduktivitas yang masih rendah. Wang et al. (2011) menghasilkan carbon black dengan konduktivitas tertinggi 21,6 
S.m $\mathrm{m}^{-1}$ dan hampir sama dengan commercial carbon black yang memiliki konduktivitas sebesar 25,3 S.m 1 . Masih rendahnya konduktivitas disebabkan masih tingginya kadar abu (oksida logam termasuk silika) yang bersifat isolatif listrik.

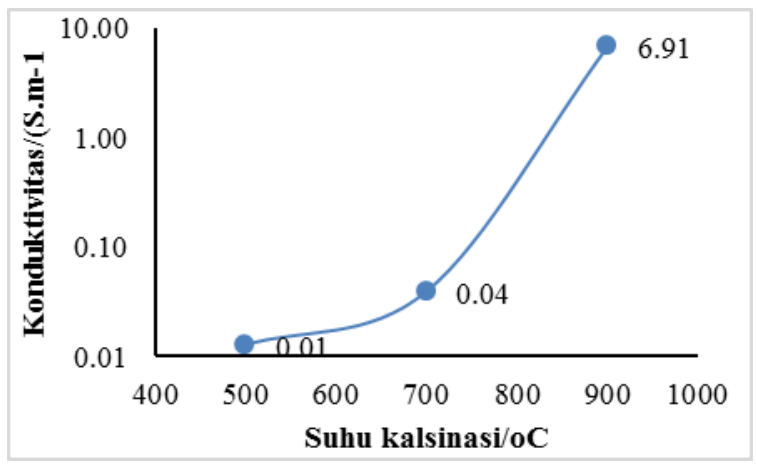

Gambar 6. Grafik suhu kalsinasi terhadap nilai konduktivitas

\section{Karakterisasi Karbon Analisis FTIR}

Gambar 9 merupakan spektrum FTIR dari karbon yang telah dikalsinasi pada suhu $500-900^{\circ} \mathrm{C}$ selama 2 jam. Pada spektrum FTIR hasil kalsinasi pada suhu $500^{\circ} \mathrm{C}$ dan $700^{\circ} \mathrm{C}$ pola spektrumya relatif sama. Lembah yang muncul pada panjang gelombang $3408 \mathrm{~cm}^{-1}$ merupakan vibrasi regang O-H, $2930 \mathrm{~cm}^{-1}$ regang $\mathrm{C}-\mathrm{H}$ alifatik, $1091 \mathrm{~cm}^{-1}$, dan $815 \mathrm{~cm}^{-1}$ vibrasi tetrahedral $\mathrm{SiO}_{4}$. Pada spektrum FTIR hasil kalsinasi pada suhu $900^{\circ} \mathrm{C}$ pola spektrumya menunjukkan perbedaan yang jelas yaitu hilangnya lembah yang tajam pada bilangan gelombang sekitar $1600 \mathrm{~cm}^{-1}$ dan timbulnya lembah tajam dengan intensitas rendah pada bilangan gelombang sekitar $470 \mathrm{~cm}^{-1}$. Hal tersebut menunjukkan telah hilangnya gugus karbonil dan terbentuk gugus $\mathrm{Si}-\mathrm{O}-\mathrm{Si}$ akibat terjadinya kondensasi Si-OH. Dengan demikian karbon hasil kalsinasi pada suhu $900^{\circ} \mathrm{C}$ mengandung karbon tetap (fixed carbon) tinggi namun masih mengandung silika dalam kadar rendah.

\section{Analisis SEM-EDS}

Gambar 10 merupakan foto SEM dari karbon sekam padi setelah pelepasan silika dengan natrium karbonat yang dikalsinasi dalam lingkungan gas argon pada suhu $900^{\circ} \mathrm{C}$ dengan pembesaran 1000x. Hasil EDX pada karbon setelah pelarutan silika dengan natrium karbonat, di bagian permukaan luarnya masih terkandung silikon (Gambar 10.A). Hal tersebut menunjukkan silika yang banyak terkandung pada permukaan luar arang tidak larut semuanya, demikian juga pada bagian lain tampak adanya silika yang terjerembap pada pori karbon (Gambar 10B). Hal tersebut menyebabkan karbon yang diperoleh masih mengandung silika yang ditunjukkan oleh kadar abu yang masih tinggi. Silika yang terdapat dalam karbon bukan hanya berasal dari silika yang terjerembap pada pori karbon namun juga berasal dari silika pada permukaan luar yang tidak larut.

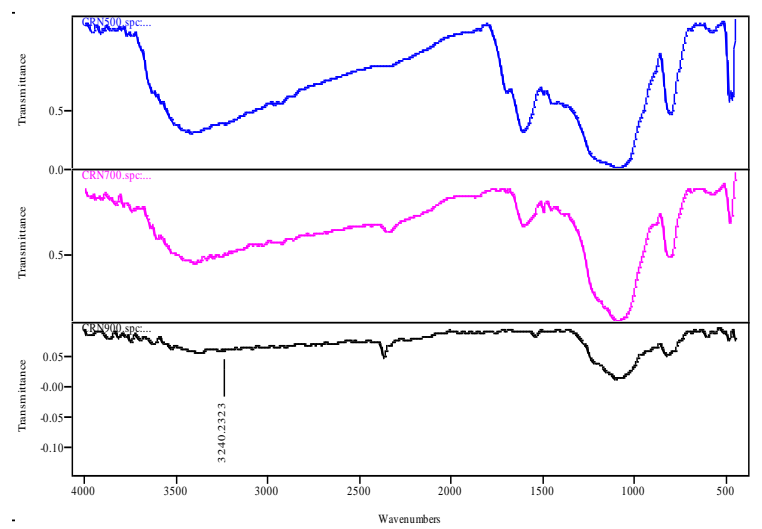

Gambar 9. Spektrum FTIR dari karbon yang telah dikalsinasi pada suhu $500-900^{\circ} \mathrm{C}$

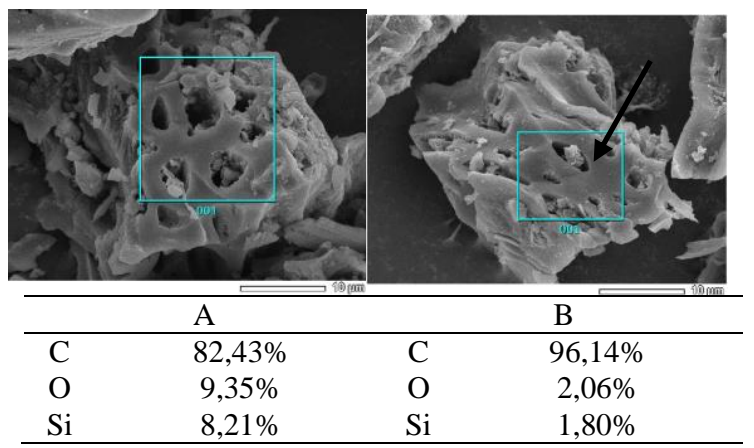

Gambar 10. Foto SEM-EDX dari karbon sekam padi setelah pelepasan silika dengan natrium karbonat

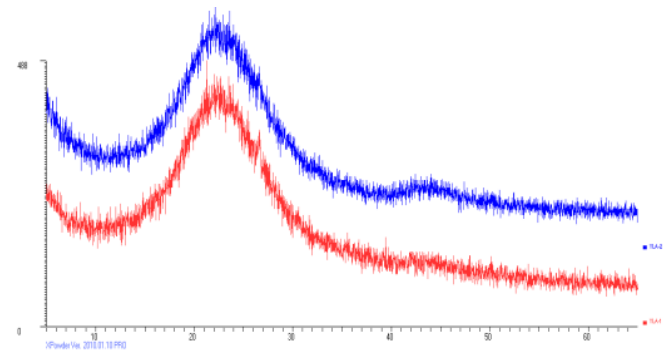

Gambar 7. Difraktogram pada arang kalsinasi $500^{\circ} \mathrm{C}$ dan $900^{\circ} \mathrm{C}$

\section{Analisis x-ray diffraction (XRD)}

Analisis XRD dilakukan pada karbon hasil kalsinasi pada suhu $500^{\circ} \mathrm{C}$ dan $900^{\circ} \mathrm{C}$ pada atmosfer gas argon (Gambar 11). Pada kedua difraktogram tersebut pola difraktogramnya hampir sama. Puncak amorfnya terlihat pada sekitar $2 \theta=23,0^{\circ}$. Nilai $2 \theta$ ini lebih rendah dari puncak yang berasal dari karbon amorf (sekitar $2 \theta=24^{\circ}$ ). Hal ini menunjukkan masih adanya silika yang relatif tinggi. Perbedaan pada terlihat pada karbon hasil kalsinasi $900^{\circ} \mathrm{C}$ terlihat adanya puncak amorf yang rendah pada sekitar $2 \theta=$ $43,9^{\circ}$. Hal ini menunjukkan telah mulai terjadi 
grafitisasi. Pola difraktogram ini menunjukkan bahwa karbon yang dihasilkan berbentuk amorf.

\section{KESIMPULAN}

Pelepasan silika paling efektif menggunakan larutan Natrium karbonat dengan rasio 1:3 melalui metode refluk. Karbon yang diperoleh mempunyai kadar abu 4,34\% dan amorf. Karbon koduktif diperoleh setelah dikalsinasi pada suhu $900^{\circ} \mathrm{C}$ selama 2 jam dengan nilai konduktivitas 20,04 S.m ${ }^{-1}$.

\section{DAFTAR PUSTAKA}

Bharadwaj, A., Wang, Y., Sridhar, S. \& Arunachalam V.S. (2004). Pyrolysis of rice husk, Current Science, 87(7), 981-986.

Deiana, C., Granados, D., Venturini, R., Amaya, A., Sergio, M. \& Tancredi, N. (2008). Activated carbons obtained from rice husk: Influence of leaching on textural parameters, Industrial and Engineering Chemistry Research, 47, 4754-4757

Farag H., White Hurst D.D. \& Mochida I. (1998). Synthesis of active hydrosulfurization carbon supported Co-Mo catalysts. Relationship between preparation methods and activity/selectivity, Industrial and Engineering Chemistry Researc,. 37, 3533-3539.

Frackowiak, E. \& Beguin, F. (2001).Carbon materials for the electrochemical storage of energy in capacitors, Carbon, 39, 937-950.

Guo,Y., Yang, S., Yu, K., Zhao, J., Wang, Z. \& Xu, H. (2002). The preparation and mechanism studies of rice husk based porous carbon. Materials Chemistry and Physics, 74, 320-323.

Liu Y., Guo, Y., Gao, W., Wang, Z., Ma,Y. \& Wang Z. (2012). Simultaneous preparation of silica and activated carbon from rice husk ash, Journal of Cleaner Production, 32, 204-209.

Liu, Y., Guo, Y., Zhu, Y., An, D., Gao, W., Wang, Z., Ma, Y. \& Wang Z. (2011). A sustainable route for the preparation of activated carbon and silica from rice husk ash, Journal of Hazardous Material, 186, 1314-1319.

Lu, C. Y., Wey, M. Y. \& Chuang, K.H. (2009). Catalytic treating of gas pollutants over cobalt catalyst supported on porous carbons derived from rice husk and carbon nanotube. Applied Catalysis B: Environmental, 90, 652-661.

Wang, L., Schnepp, Z. \& Titirici, M.M. (2013). Rice husk-derived carbon anodes for lithium ion batteries, Journal of Materials Chemistry A, 17: 5269-5273.

Worasuwannarak, N., Sonobe, T., \& Tanthapanichakoon, W. (2007). Pyrolysis behaviors of rice straw, rice husk, and corncob by TG-MS technique, Journal of Analytical and Applied Pyrolysis, 78, 265-271.

Yeletsky, P.M., Yakovlev, V.A., Mel'gunov, M.S. \& Parmon V.N. (2009). Synthesis of mesoporous carbons by leaching out natural silica templates of rice husk, Microporous and Mesoporous Materials, 121, 34-40. 